\title{
Chromogenic and Fluorogenic Sensing of Biological Thiols in Aqueous Solutions Using BODIPY-Based Reagents
}

2013

Vol. 15, No. 1

216-219

\author{
Murat Isik, ${ }^{\ddagger}$ Tugba Ozdemir, ${ }^{\ddagger}$ Ilke Simsek Turan, ${ }^{\ddagger}$ Safacan Kolemen, ${ }^{\ddagger}$ and \\ Engin U. Akkaya*,t,‡ \\ Department of Chemistry and UNAM-National Nanotechnology Research Center, \\ Bilkent University, 06800 Ankara, Turkey \\ eua@fen.bilkent.edu.tr
}

Received December 2, 2012

\section{ABSTRACT}

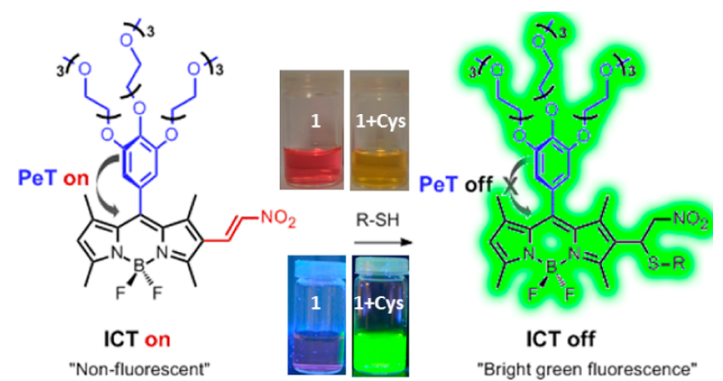

Judicious design of BODIPY dyes carrying nitroethenyl substituents in conjugation with the BODIPY core yields dyes that respond to biological thiols by both absorbance and emission changes. Incorporation of solubilizing ethyleneglycol units ensures water solubility. The result is bright signaling of biologically relevant thiols in the longer wavelength region of the visible spectrum and in aqueous solutions.

Sensing and signaling of biological thiols is at the focus of recent flurry of work. ${ }^{1}$ These reaction-based probes take advantage of high nucleophilicity of thiol functions found in biologically relevant species such as Cystein (Cys), Homocystein (Hcy) and Glutathione (GSH). These biothiols are vital for the maintenance of cellular redox status and alterations in their levels is linked to a number of debilitating diseases such as AIDS, cancer and Alzheimer's. ${ }^{2}$ Consequently, probes that respond to these thiols by color change, emission change, or both are highly valued. If they are made to function in aqueous solutions, naturally, they are deemed to be more desirable considering potential applications.

We now present a nitroethenyl-BODIPY conjugate 1, having both chromogenic and fluorescence turn-on

$\dagger$ Department of Chemistry

WNAM-National Nanotechnology Research Center

(1) (a) Chen, X.; Zhou, Y.; Peng, X.; Yoon, J. Chem. Soc. Rev. 2010, 39, 2120. (b) Zhou, Y.; Yoon, J. Chem. Soc. Rev. 2012, 41, 51. (c) Jun, M. E.; Roy, B.; Ahn, K. H. Chem. Commun 2011, 47, 7583.

(2) (a) Zhang, S. Y.; Ong, C.-N.; Shen, H.-M. Cancer Lett. 2004, 208, 143. (b) Pastore, A.; Piemonte, F.; Locatelli, M.; Lo Russo, A.; Gaeta, L. M.; Tozzi, G.; Federici, G. Clin. Chem. 2001, 47, 1467. (c) Townsend, D. M.; Tew, K. D.; Tapiero, H. Biomed. Pharmacother. 2003, 57, 145. responses for fast, selective and sensitive detection of biological thiols in aqueous media. The roles of three separate modules of the thiol probe $\mathbf{1}$ are displayed in Scheme 1 and can be described as follows: (1) Boron dipyrromethene $(\text { BODIPY })^{3}$ fluorophore was chosen as the signaling unit for its widely accepted superiority (e.g., high molar absorptivity, high photostability, visible wavelength absorption and its modular nature for facile functionalization, etc.) over more conventional alternatives. Because of these unique features, a plethora of fluorescent sensors/labels, ${ }^{4}$

(3) (a) Ziessel, R.; Ulrich, G.; Harriman, A. New. J. Chem. 2007, 31, 496. (b) Loudet, A.; Burgess, K. Chem. Rev. 2007, 107, 4891. (c) Ulrich, G.; Ziessel, R.; Harriman, A. Angew. Chem., Int. Ed. 2008, 47, 1184.

(4) (a) Sunahara, H.; Urano, Y.; Kojima, H.; Nagano, T. J. Am. Chem. Soc. 2007, 129, 5597. (b) Baruah, M.; Qin, W. W.; Vallee, R.; Beljonne, D.; Rohand, T.; Dehaen, W.; Boens, N. Org. Lett. 2005, 7, 4377. (c) Yin, S. C.; Leen, V.; Van Snick, S.; Boens, N.; Dehaen, W. Chem. Commun 2010, 46, 6329. (d) Qi, X.; Kim, S. K.; Han, S. J.; Xu, L.; Jee, A. Y.; Kim, H. N.; Lee, C.; Kim, Y.; Lee, M.; Kim, S. J.; Yoon, J. Tetrahedron Lett. 2008, 49, 261. (e) Niu, S.; Massif, C.; Ulrich, G.; Renard, P.; Romieu, A.; Ziessel, R. Chem-Eur. J. 2012, 18, 7229. (f) Rurack, K.; Kollmansberger, M.; Resch-Genger, U.; Daub, J. J. Am. Chem. Soc. 2000, 122, 968. (g) Bozdemir, O. A.; Guliyev, R.; Buyukcakir, O.; Selcuk, S.; Kolemen, S.; Gulseren, G.; Nalbantoglu, T.; Boyaci, H.; Akkaya, E. U. J. Am. Chem. Soc. 2010, 132, 8029. (h) Atilgan, S.; Ozdemir, T.; Akkaya, E. U. Org. Lett. 2010, 47, 4792. 
light harvesting systems, ${ }^{5}$ photodynamic therapy agents ${ }^{6}$ and molecular logic gate systems ${ }^{7}$ are built around BODIPY cores, and these received considerable attention from the chemical community. (2) Incorporation of a nitroalkene unit to the parent dye would transform it into a strong Michael acceptor, which would be highly susceptible to sulfhydryl nucleophiles. ${ }^{8}$ Indeed, Michael reaction-based thiol sensing protocols ${ }^{9}$ clearly emerge as the favorite among other strategies. ${ }^{10}$ Nucleophilic attack of the thiol to the $\beta$-position of nitroethene is expected to disrupt the $\pi$-conjugation and block the intramolecular charge transfer (ICT) process, which is expected to induce a blue shift in absorbance. (3) Gallic acid derived unit placed at the mesoposition of BODIPY core plays two crucial functions: (i) photoinduced-electron-transfer (PeT)-based modulation of the emission, as the electron rich trimethoxyphenyl moiety could quench excited state of the electron deficient (due to conjugated nitroethenyl group) BODIPY core by

(5) (a) Zhang, X.; Xiao, Y.; Qian, X. Org. Lett. 2008, 10, 29. (b) Iehl, J.; Nierengarten, J.-F.; Harriman, A.; Bura, T.; Ziessel, R. J. Am. Chem. Soc. 2012, 143, 988. (c) Bozdemir, O. A.; Cakmak, Y.; Sozmen, F.; Ozdemir, T.; Siemiarczuk, A.; Akkaya, E. U. Chem.-Eur. J. 2010, 16, 6346. (d) Bozdemir, O. A.; Erbas-Cakmak, S.; Ekiz, O. O.; Dana, A.; Akkaya, E. U. Angew. Chem., Int. Ed. 2011, 50, 10907.

(6) (a) Kamkaew, A.; Lim, S. H.; Lee, H. B.; Kiew, L. V.; Chung, L. Y.; Burgess, K. Chem. Soc. Rev. 2013, 42, 77. (b) Yogo, T.; Urano, Y.; Ishitsuka, F.; Nagano, T. J. Am. Chem. Soc. 2005, 127, 12162. (c) Gallagher, W. M.; Allen, L. T.; O'Shea, C.; Kenna, T.; Hall, M.; Gorman, A.; Killoran, J.; O'Shea, D. F. J. Cancer 2005, 92, 1702. (d) Erbas, S.; Gorgulu, A.; Kocakusakogullari, M.; Akkaya, E. U. Chem. Commun. 2009, 4956. (e) Cakmak, Y.; Kolemen, S.; Duman, S.; Dede, Y.; Dolen, Y.; Kilic, B.; Kostereli, Z.; Yildirim, L. T.; Dogan, A. L.; Guc, D.; Akkaya, E. U. Angew. Chem., Int. Ed. 2011, 50, 11937.

(7) (a) Guliyev, R. Ozturk, S.; Kostereli, Z.; Akkaya, E. U. Angew. Chem., Int. Ed. 2011, 50, 9826. (b) Coskun, A.; Deniz, E.; Akkaya, E. U. Org. Lett. 2005, 7, 5187.

(8) Two nitroolefin-attached fluorescent thiol sensors were published during the preparation of this manuscript. See: (a) Sun, Y.-Q.; Chen, M.; Liu, J.; Lv, X.; Li, J.-f.; Guo, W. Chem. Commun. 2011, 47, 11029. (b) Zhang, M.; Wu, Y.; Zhang, S.; Zhu, H.; Wu, Q.; Jiao, L.; Hao, E. Chem. Commun. 2012, 48, 8925.

(9) (a) Yang, X.; Guo, Y.; Strongin, R. M. Angew. Chem., Int. Ed. 2011, 50, 10690. (b) Lim, S.; Escobedo, J. O.; Lowry, M.; Xu, X.; Strongin, R. Chem. Commun. 2010, 46, 5707. (c) Ros-lis, J. V.; Garcia, B.; Jimenez, D.; Martinez-Manez, R.; Sancenon, F.; Soto, J.; Gonzalvo, F.; Valldecabres, M. C. J. Am. Chem. Soc. 2004, 126, 4064. (d) Hong, V.; Kislukhin, A. A.; Finn, M. G. J. Am. Chem. Soc. 2009, 131, 9986. (e) Huo, F. J.; Sun, Y.-Q.; Su, J.; Chao, J. B.; Zhi, H. J.; Yin, C. X. Org. Lett. 2009, 11, 4918. (f) Jung, H. S.; Ko, K. C.; Kim, G.; Lee, A.; Na, Y.; Kang, C.; Lee, J. Y.; Kim, J. S. Org. Lett. 2011, 13, 1498. (g) Yuan, L.; Lin, W.; Yang, Y. Chem. Commun. 2011, 47, 6275. (h) Lin, W.; Yuan, L.; Cao, Z.; Feng, Y.; Long, L. Chem.-Eur. J. 2009, 15, 5096. (i) Chen, X.; Ko, S.; Kim, M. J.; Shin, I.; Yoon, J. Chem. Commun. 2010, 46, 2751. (j) Lee, J.; Lee, S.; Zhai, D.; Ahn, Y.; Yeo, H. Y.; Tan, Y. L.; Chang, Y. Chem. Commun. 2011, 47, 4508. (k) Sun, Y.; Chen, M.; Liu, J.; Lv, X.; Li, J.; Guo, W. Chem. Commun. 2011, 47, 11029. (l) Kwon, H.; Lee, K.; Kim, H. Chem. Commun. 2011, 47, 1773. (m) Kim, G.; Lee, K.; Kwon, H.; Kim, H. Org. Lett. 2011, 13, 2799.

(10) (a) Rusin O. St; Luce, N. N.; Agbaria, R. A ; Escobedo, J. O. Jiang, S.; Warner, I. M.; Dawan, F. B.; Lian, K.; Strongin, R. M. J. Am. Chem. Soc. 2004, 126, 438. (b) Lin, W.; Long, L.; Yuan, L.; Cao, Z.; Chen, B.; Tan, W. Org. Lett. 2008, 10, 5577. (c) Lin, H.; Fan, J.; Wang, J.; Tian, M.; Du, J.; Sun, S.; Sun, P.; Peng, X. Chem. Commun. 2009, 5904. (d) Lee, J. H.; Lim, C. S.; Tian, Y. S.; Han, J. H.; Cho, B. R. J. Am. Chem. Soc. 2010, 132, 1216. (e) Tang, B.; Xing, Y.; Li, P.; Zhang, N.; Yu, F.; Yang, G. J. Am. Chem. Soc. 2007, 129, 11666. (f) Yao, Z.; Feng, X.; Li, C.; Shi, G. Chem. Commun. 2009, 5886. (g) Hewage, H. S.; Anslyn, E. V. J. Am. Chem. Soc. 2009, 131, 13099. (h) Sibrian-Vazquez, M.; Escobedo, J. O.; Lim, S.; Samoei, G. K.; Strongin, R. M. Proc. Natl. Acad. Sci. U. S. A. 2010, 107, 551. (i) Zhang, M.; Yu, M.; Li, F.; Zhu, M.; Li, M.; Gao, Y.; Li, L.; Liu, Z.; Zhang, J.; Yi, T.; Huang, C. J. Am. Chem. Soc. 2007, 129, 10322. (j) Guo, Z.; Nam, S.; Park, S.; Yoon, J. Chem. Sci 2012, 3, 2760. an electron transfer and (ii) ethyleneglycolic entities anchored on phenolic hydroxyl functionalities should facilitate water solubility, enhancing the chances for practical applications of the probe $\mathbf{1}$.

Scheme 1. Design Elements of the Nitroethenyl-BODIPY Conjugate Thiol Probe 1
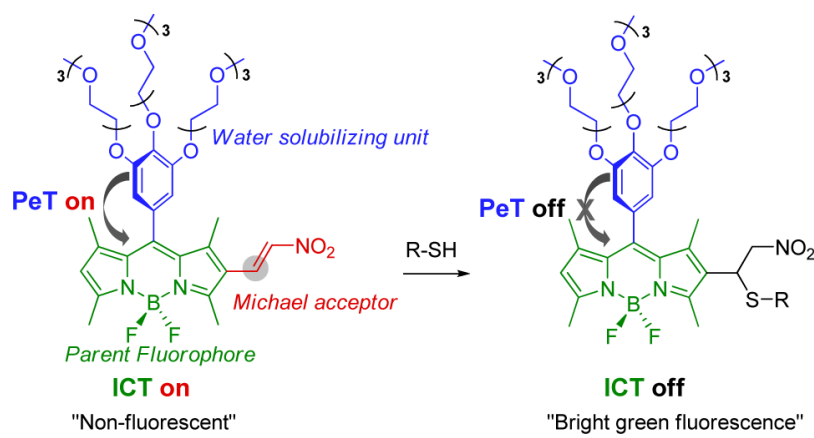

ICT off

"Bright green fluorescence"

To test the aforementioned hypothesis, we set out to synthesize a simpler analogue of $\mathbf{1}$ and studied its 1,4addition reactivity with thiols. Thiol sensor 2 was prepared from the readily available 2-formylBODIPY ${ }^{6 \mathrm{e}}$ precursor via tandem Henry/elimination reaction (see Supporting Information). Once $\beta$-mercaptoethanol (ME), chosen as the simple biothiol model compound, reacted with the thiol sensor 2, an apparent color change from red to orange was noticed. This bright green fluorescing adduct 3 was presumed to be the 1,4-conjugate addition product (Figure 1). Because of poor solubility of $\mathbf{2}$ in common polar organic solvents, absorption and emission spectra were not recorded. Michael reaction of $\mathbf{2}$ and ME was amenable to ${ }^{1} \mathrm{H}$ NMR spectroscopy analysis. Comparison of ${ }^{1} \mathrm{H}$ NMR spectra of $\mathbf{2}$ and $\mathbf{3}$ clearly shows that the addition of ME to the sensor 2 leads to the disappearance of the vinylic protons $\left(\mathrm{H}_{a}\right.$ and $\left.\mathrm{H}_{b}\right)$ resonating at 8.07 and $7.44 \mathrm{ppm}$ with the concomitant appearance of $\alpha$-protons of the newly formed nitroalkane showing at $4.80 \mathrm{ppm}$. About $0.1 \mathrm{ppm}$ upfield shift of aromatic hydrogens (meso- $\mathrm{H}$ and $6-\mathrm{H})$

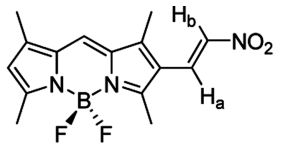

2

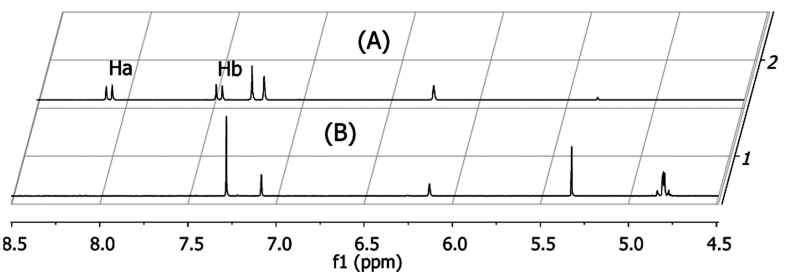

Figure 1. Stacked partial ${ }^{1} \mathrm{H}$ NMR spectra of thiol probe 2 (A) and conjugate addition product 3 (B) in $\mathrm{CDCl}_{3}$ at $25^{\circ} \mathrm{C}$. 
of BODIPY core is an indication of an increase in the electron density of the BODIPY core (the signaling unit) upon conjugate addition.

Once we demonstrated the Michael acceptor reactivity of the nitroethenyl-BODIPY derivative 2 toward the thiol ME, we have turned our attention to the water-soluble derivative 1. Synthetic route followed is depicted in Scheme 2.

Scheme 2. Synthesis of the Water-Soluble Thiol Probe 1
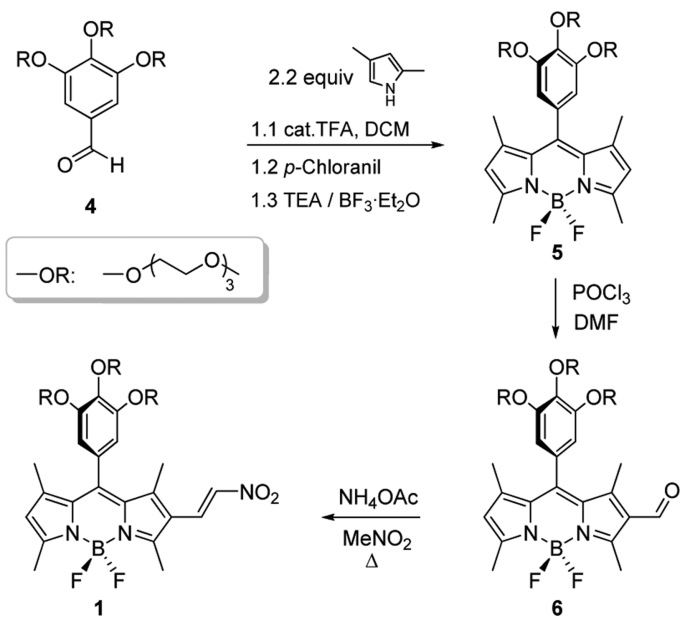

Gallic acid derived aldehyde $\mathbf{4}$ was prepared according to our previous report ${ }^{11}$ and reacted with 2,4-dimethylpyrrole to furnish $\mathbf{5}$. Fluorescent dye $\mathbf{5}$ was formylated via Vilsmeier-Haack reaction in good yield, and subsequent condensation in nitromethane in the presence of catalytic amount of $\mathrm{NH}_{4} \mathrm{OAc}(20 \mathrm{~mol} \%)$ provided the thiol probe 1 in reasonable overall yields $(14 \%)$.

Figure 2 shows the electronic absorption and fluorescence emission response of the thiol probe $1(2.4 \mu \mathrm{M})$ in $50 \mathrm{mM}$ HEPES: $\mathrm{CH}_{3} \mathrm{CN}(80: 20, \mathrm{v} / \mathrm{v}, \mathrm{pH}=7.20)$ to increasing Cysteine (Cys) concentrations ( $0-400$ equiv).
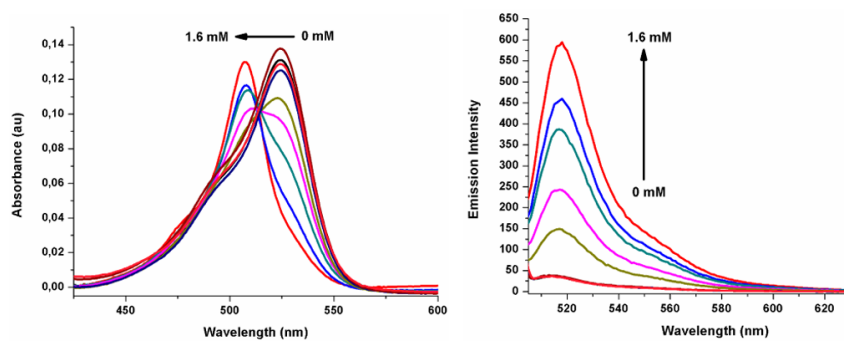

Figure 2. UV-vis absorption spectra (left) and fluorescence spectra (right) of the thiol probe $1(2.4 \mu \mathrm{M})$ upon increased Cys concentrations $\left(0-400\right.$ equiv) in $50 \mathrm{mM}$ HEPES: $\mathrm{CH}_{3} \mathrm{CN}$ $\left(80: 20, \mathrm{v} / \mathrm{v}, \mathrm{pH}=7.20, \lambda_{\text {ex }} 500 \mathrm{~nm}\right.$ at $\left.25^{\circ} \mathrm{C}\right)$.

Upon addition of Cys, absorption band of free dye $\mathbf{1}$ centered at $525 \mathrm{~nm}$ gradually decreased, and a new band

(11) Atilgan, S.; Ekmekci, Z.; Dogan, A. L.; Guc, D.; Akkaya, E. U. Chem. Commun. 2006, 4398. appeared with a maximum at $510 \mathrm{~nm}$. A $15 \mathrm{~nm}$ blue shift with a well-defined isosbestic point at $518 \mathrm{~nm}$ is apparent from the absorption spectrum (Figure 2, left). This Cys-induced hypsochromic shift reveals the suppression of ICT process that occurs between donor BODIPY core and acceptor nitroalkene unit, as predicted. Probe $\mathbf{1}$ is essentially nonfluorescent $\left(\Phi_{\mathrm{f}}=0.056\right)$ as evidenced by emission spectrum (Figure 2, right). Fluorescence intensity increases up to 20-fold (Figure 2) upon increasing Cys concentrations ( $0-400$ equiv) with an emission band centered at $515 \mathrm{~nm}\left(\lambda_{\mathrm{ex}} 500 \mathrm{~nm}\right)$. In agreement with our design expectations, this fluorescence enhancement is at least partly due to a reduction in the efficiency of the PeT process upon the attack of the Cys thiol on probe 1 resulting an increase in the energy level of the BODIPY centered LUMO. Under identical conditions, other biological thiols, such as Homocysteine (Hcy) and Glutathione (GSH), afforded similar turn on fluorescence responses as well (Figures S1 and S2, Supporting Information). However, the response to Cys is much faster than that to Hcy and GSH. Thus, by controlling the reaction time, exquisite selectivity for Cys can be obtained (Figure S9, Supporting Information, and inset in Figure 3).

Sensing experiments were also carried out in HEPES: $\mathrm{CH}_{3} \mathrm{CN}(60: 40, \mathrm{v} / \mathrm{v})$ and 100\% HEPES buffer solutions (pH 7.2 in both). While $40 \%$ acetonitrile solution produces essentially the same responses as that of $20 \%$ acetonitrile solution, fluorescence response of $\mathbf{1}$ toward biological thiols was halved in 100\% HEPES solution (Figures S3 and S4, Supporting Information), but the signal is still strong enough for sensitive and selective detection of thiols (vide infra).

As a natural extension of this study, we have investigated the selectivity of probe 1 toward Cys, Hys and GSH over potentially competing biologically relevant natural amino

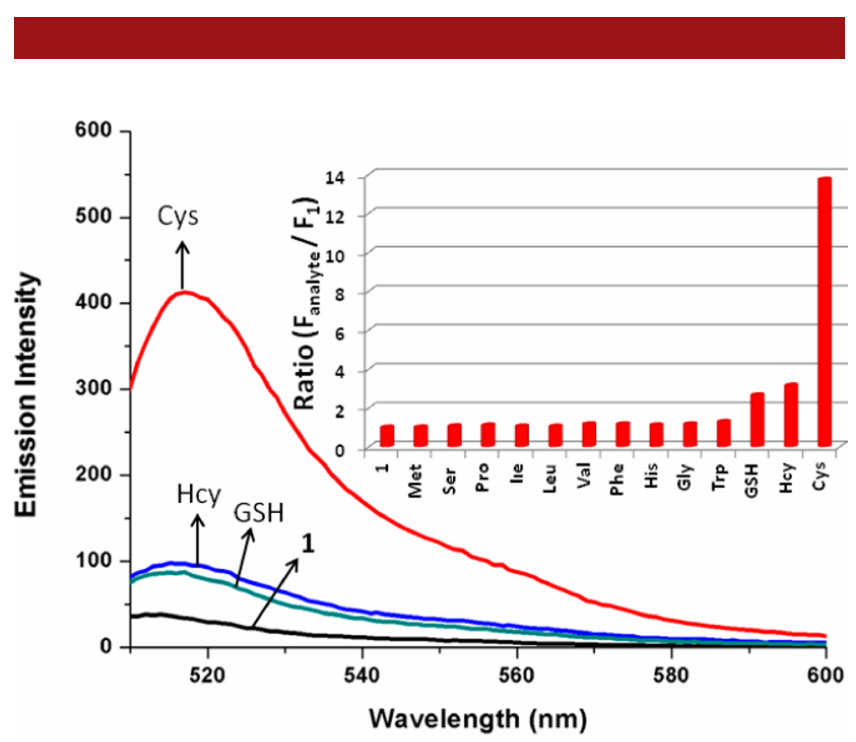

Figure 3. Fluorescence response of the thiol probe $1(2.4 \mu \mathrm{M})$ toward biothiols (Cys, Hcy and GSH; 200 equiv each) and other natural amino acids (400 equiv) in $50 \mathrm{mM}$ HEPES: $\mathrm{CH}_{3} \mathrm{CN}$ $\left(80: 20, \mathrm{v} / \mathrm{v}, \mathrm{pH}=7.20, \lambda_{\mathrm{ex}} 500 \mathrm{~nm}\right.$ at $\left.25^{\circ} \mathrm{C}\right)$. 
Scheme 3. Red-Emitting Nitroolefin-BODIPY Conjugate Thiol Probe 7

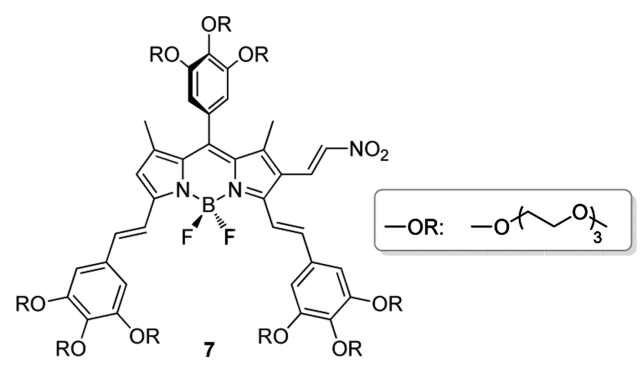

Table 1. Optical Properties of the Probes 1 and 7

\begin{tabular}{ccccc}
\hline compound $^{a}$ & $\lambda_{\text {abs }}(\mathrm{nm})$ & $\lambda_{\text {em }}(\mathrm{nm})$ & $\Phi_{\mathrm{f}}{ }^{b}$ & $\varepsilon_{\max }{ }^{c}$ \\
\hline $\mathbf{1}$ & 525 & 540 & $0.056^{d}$ & 58500 \\
$\mathbf{7}$ & 623 & 655 & $0.016^{e}$ & 51800
\end{tabular}

${ }^{a}$ Data acquired in $50 \mathrm{mM}$ HEPES: $\mathrm{CH}_{3} \mathrm{CN}(80: 20, \mathrm{v} / \mathrm{v}, \mathrm{pH}=7.20)$, in dilute solutions. ${ }^{b}$ Relative quantum yields. ${ }^{c}$ Unit: $\mathrm{cm}^{-1} \mathrm{M}^{-1}$. ${ }^{d}$ Reference dye: Rhodamine $6 \mathrm{G}$ in water $\left(\Phi_{\mathrm{f}}=0.95\right) .{ }^{e}$ Reference dye: Cresyl violet in methanol $\left(\Phi_{\mathrm{f}}=0.90\right)$

acids in HEPES: $\mathrm{CH}_{3} \mathrm{CN}(80: 20, \mathrm{v} / \mathrm{v})$ at physiological $\mathrm{pH}$ (7.20). No significant change was observed in both absorption (Supporting Information) and fluorescence emission (Figure 3) spectra when natural amino acids other than cysteine were treated with the probe 1 .

Extending the sensing range of the probe into the red and near IR would be highly advantageous. To that end, we made use of now established protocols for Knoevenagel condensation of the methyl substituted BODIPYs and aldehydes. As probe $\mathbf{1}$ was derivatized by reacting with a trialkoxybenzaldehyde, the absorbance and fluorescence maxima moved into far red ( $\lambda_{\text {abs }} 623 \mathrm{~nm}$ and $\left.\lambda_{\text {em }} 650 \mathrm{~nm}\right)$ with enhanced water solubility as a bonus (Scheme 3 and Table 1).

Synthesis of distyryl-BODIPY 7 was achieved in 3 steps starting from compound $\mathbf{5}$ (Supporting Information). Optical properties of $\mathbf{1}$ and $\mathbf{7}$ are given below in Table 1 . Compared to $\mathbf{1}$, dye $\mathbf{7}$ has an extended $\pi$-conjugation that causes significant bathochromic shift $(\approx 100 \mathrm{~nm}$ in absorption and $\approx 125 \mathrm{~nm}$ in emission peaks). However, this extension of conjugation diminished the fluorescence quantum yield of $\mathbf{7}$ to approximately one-third of probe $\mathbf{1}$.

Sensor 7 displayed good water solubility due to the presence of nine triethyleneglycolic arms on the styryl

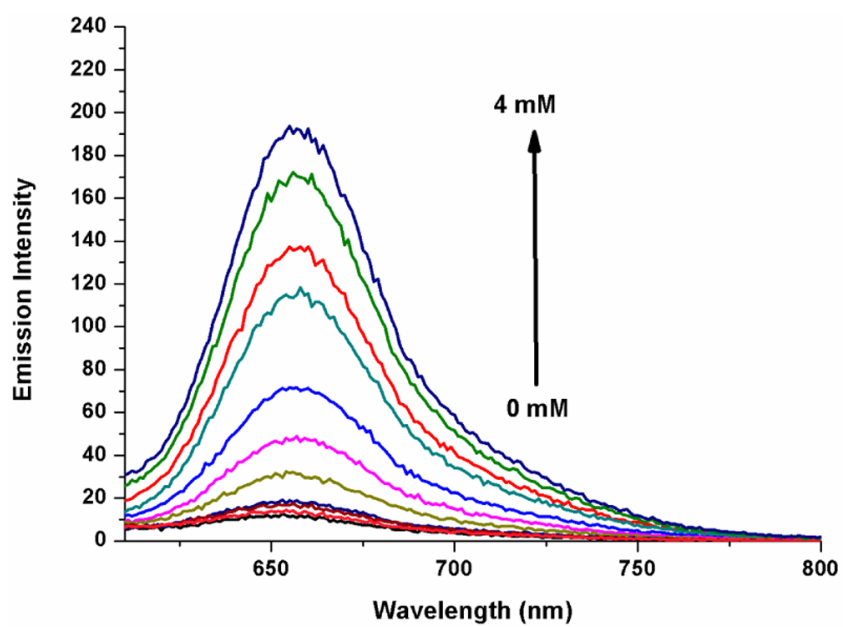

Figure 4. Fluorescence spectra of the red-emitting thiol probe 7 $(2.4 \mu \mathrm{M})$ upon increased Cys concentrations $(0-1000$ equiv) in $50 \mathrm{mM}$ HEPES: $\mathrm{CH}_{3} \mathrm{CN}\left(80: 20, \mathrm{v} / \mathrm{v}, \mathrm{pH}=7.20, \lambda_{\text {ex }} 600 \mathrm{~nm}\right.$ at $25^{\circ} \mathrm{C}$ ).

and meso substituents. Absorption (Figure S7, Supporting Information) and fluorescence response (Figure 4) of this red-emitting chromophore 7 were also examined. An equal magnitude of enhancement response was observed with the probe 7 and $\mathbf{1}$ upon incremental Cys additions $(0-400$ equiv).

In conclusion, two nitroethenyl-BODIPY derivatives (1 and 7) operating at different wavelengths were designed, synthesized and evaluated for biological thiol (Cys, Hcy and GSH) sensing in aqueous solutions. Both probes showed very fast and sensitive responses with color changes and "turn-on" fluorescence. We are confident that an understanding of BODIPY photophysics in relation to PeT efficiency and internal charge transfer would produce newer and more capable sensors for analytes of interest. Compounds $\mathbf{1}$ and $\mathbf{7}$ are two examples along that promising road.

Acknowledgment. This research was supported by TUBITAK (112T480). We thank Ms. Asli Celebioglu for the digital photographs.

Supporting Information Available. Methods, experimental procedures, additional spectral data. This material is available free of charge via the Internet at http:// pubs.acs.org.

The authors declare no competing financial interest. 